are aware of differing rates of referral for ductal ligation from neonatal units within our own catchment area, but whether this is the result of different management or differen case mix is uncertain. The statement in the abstract is, we agree, not supported by a controlled study, which we are not in a position to perform.

\section{Absent or reversed end diastolic flow velocity in the umbilical artery and necrotising enterocolitis}

SIR,-We read the paper of Malcolm et al with interest, and noted the close association between absent or reversed end diastolic flow (AREDF) velocities in the umbilical artery in high risk pregnancies and neonatal necrotising enterocolitis. ${ }^{1}$ We wish to add some data that supports the hypothesis that it is AREDF, independent of growth retardation and prematurity, which predisposes to necrotising enterocolitis.

A prospective study of all patients attending a high risk fetal assessment clinic was performed over a two year period in this hospital. Umbilical artery flow velocity waveforms were studied using a Doppler Mark V Duplex scanner in pregnancies complicated by hypertension and/or intrauterine growth retardation. There were 20 cases where AREDF was identified in the umbilical artery of a morphologically normal fetus; of these, two were intrauterine deaths. The 18 liveborn fetuses were matched for gestational age and birth weight with 18 liveborn tetuses from the same cohort who had never had AREDF. The mean (SD) gestational ages were $32 \cdot 2(2 \cdot 9)$ and $32.6(1 \cdot 9)$ weeks respectively for cases and controls and mean (SD) birth weights were 1323 (544) and 1489 (386) g. The mortality rate was $30 \%(6 / 20)$ for fetuses with AREDF; none of the controls died. Necrotising enterocolitis (defined as clinical features suggestive of necrotising enterocolitis confirmed by radiological evidence of intramural or portal air) occurred in four (22\%) of the babies who had had AREDF compared with one (6\%) of the control babies.

$$
\begin{array}{r}
\text { D C WILSON } \\
\text { A HARPER } \\
\text { G MCCLURE } \\
\text { Royal Maternity Hospital, } \\
\text { Grosvenor Road, } \\
\text { Belfast BT12 6BB }
\end{array}
$$

1 Malcolm G, Ellwood D, Devonald K, Belby R, Henderson-Smart D. Absent or reversed end diastolic flow velocity in the umbilical artery and necrotisin

Body water measurements in growth disorders

SIR,-The ability of bioelectrical impedance to estimate body composition in the paediatric population is a subject of burgeoning interest. Two equations have now been published that relate height ${ }^{2} /$ impedance $\left(\mathrm{H}^{2} / \mathrm{I}\right)$ to total body water by simple regression equations. ${ }^{12}$ It is noteworthy that these two equations, based upon children with large variations in height, weight and age, are remarkably similar and this has led us to combine the raw data.

The new regression equation is therefore: total body water (litres) $=0.13+0.58 \mathrm{H}^{2} / \mathrm{I}$ with a standard error of estimate of 1.3 litres.

This equation is based on 60 measurements of bioelectrical impedance and total body water using $\mathrm{H}_{2}{ }^{18} \mathrm{O}$ isotopic dilution in children aged 5.2 to 17.9 years. It is hoped that this equation may be of use to those using impedance techniques in children.

$$
\begin{array}{r}
\text { PETER S W DAVIES } \\
\text { Infant and Child Nutrition Group, } \\
\text { Dunn Nutrition Unit, } \\
\text { Milton Road, } \\
\text { Cambridge CB4 IXf } \\
\text { J W GREGORY } \\
\text { Department of Child Health, } \\
\text { The Medical School, } \\
\text { Framlington Place, } \\
\text { Newcastle upon Tyne NE2 4HH }
\end{array}
$$

1 Davies PSW, Preece MA, Hicks CJ, Halliday D. The prediction of total body water using bioelectrical impedance in children and adolescents. Ann Hum Biol 1988;15:237-41.

2 Gregory JW, Greene SA, Scrimgeour CM, Rennie MJ. Body water measurements in growth disorders: a comparison of bioelectrical impedance and skinfold thickness techniques with isotope dilution. Arch Dis Child 1991;66: 220-2. 